\title{
PARADIGMA PEMBANGUNAN EKONOMI; SATU ANALISIS TINJAUAN ULANG DARI PERSPEKTIF EKONOMI ISLAM
}

\author{
Syamsuri
}

Fakultas Ekonomi Manajemen, Universitas Darussalam (UNIDA) Gontor

Abstrak. Paradigma Pembangunan Ekonomi; Satu Analisis Tinjauan Ulang Dari Perspektif Ekonomi Islam. Kegagalan sistem ekonomi kapitalis yang membenarkan orang kaya mengeksploitasi orang miskin, dan sistem sosialis membenarkan orang miskin merampas harta orang kaya menjadi satu isu penting bagi para ekonom muslim. Paradigma kedua sistem liberal tersebut bersifat eksploitatif dan tidak fair serta memperlakukan manusia bukan sebagai manusia. Mengesampingkan nilai moral dan akhlak, memisahkan antara agama dengan ekonomi, dan menjadikan manusia hamba pembangunan, bukan pembangunan untuk manusia. Makalah ini merupakan satu refleksi fenomena dari kerusakan alam, ketimpangan sosial, kemiskinan yang tidak berkunjung reda. Sehingga teori dan konsep ekonomi liberal perlu ditinjau ulang dengan menyajikan satu konsep pembangunan ekonomi baru yang bersumber dari wahyu yaitu al-Quran maupun hadith. Akhirnya dari pembahasan dapat disimpulkan bahwa pembangunan ekonomi tidak akan dapat dicapai melainkan dengan menjalankan ajaran Islam secara kaffah, dan sifat pembangunan mestilah multi dimensi yang merangkumi pemuasan secara fisik maupun ruh. Termasuk pembangunan ekonomi juga mesti dapat menciptakan keseimbangan antara kepentingan individu dan kepentingan masyarakat, kebaikan yang seimbang dan konsisten sesuai kaedah-kaedah agama Islam. Tolak ukur keberhasilan pembangunan ini apabila tuntutan khilafah, 'adalah dan tazkiyah dapat memenuhi seluruh keperluan dasar setiap insan dan pelestarian alam sekitar untuk jangka panjang generasi selanjutnya

Kata Kunci: Pembangunan ekonomi, khilafah, 'adalah dan tazkiyah.

Abstract. Paradigm of Economic Development; Perspective of Islamic Economics Analysis. The capitalist economic system has failed because the rich exploiting the poor and a socialist economic system justifies the poor seize property of the rich. This problem becomes an important issue for the Muslim economists. Paradigm both the liberal system is exploitative, unfair and treats people not as people. Not pay attention to moral values and akhlaqs, a dichotomy between religion and economics, make man a slave of development and not development for human. This paper is a reflection phenomenon of damage to the environment, social inequality and poverty not been abated. So the liberal economic theories and concepts need to be reviewed by presenting a new economic development concept that comes from revelation that is the Quran and hadith. Finally, from the discussion can be concluded that economic development can not be achieved except with implementing Islamic guidance in everything. And the nature of development must necessarily multi-dimensional, included the gratification of physical and ruh. Economic development must also be able to create a balance between 
Islamiconomic: Jurnal Ekonomi Islam Vol.7 No.2 Juli - Desember 2016

individual interests and the interests of society, kindness balanced and consistent according the rules of Islam. Measure of the success of development if the concept of caliphate, 'adalah, and tazkiyah can meet all basic needs of every human being and nature conservation around for the long term future generations.

Keywords: Economic Development, Khilafah, 'Adalah, Tazkiyah.

\section{Pendahuluan}

Sistem politik ekonomi keagamaan (siyasah shar'iyyah) yang meletakkan agama dan akhlak sebagai dasar utama dalam pembaharuan maupun pembangunan yang sempurna berpedoman pada teori agama Islam, dengan tujuan kebahagiaan di dunia dan akhirat. ${ }^{1}$ Islam sebagai sistem tatanan hidup (way of life) yang merangkumi ajaran yang shumul (universal), senantiasa memberikan solusi yang manusiawi (humanistic), berdasarkan nilai-nilai yang terkandung di dalam al-Quran maupun Hadith.

Ajaran Islam tidak menitikberatkan pada satu aspek, seperti perilaku dalam ibadah saja (hablu mina al-Allah), atau dalam muamalah saja (hablu mina al-nas) melainkan kedua-dua aspek ini turut mendapat porsi yang sama, baik itu bersifat vertical maupun horizontal berjalan secara seimbang. Oleh karena itu, ajaran Islam tidak hanya membahas tentang pembahasan tata cara dalam upacara keagamaan (ritual) saja, namun Islam memiliki aturan yang lengkap untuk kehidupan manusia (perekonomian). Bukti nyata bahwa Islam memperhatikan permasalah ekonomi merujuk kajian Mustaq Ahmad yaitu al-Quran telah menuliskan pembahasan tentang ekonomi kurang lebih 370 kali. $^{2}$ Keseimbangan perhatian ajaran Islam antara ibadah dan muamalah juga dapat diperhatikan dari firmanNya dalam surah al-Jumuah ayat 9-10, yang mewajibkan umatnya untuk segera melaksakan solat dan meninggalkan seluruh aktivitas ekonomi ketika tiba waktunya, kemudian apabila telah selesai untuk segera mencari rezeki Allah SWT.

Sistem ekonomi Islam tidaklah sama dengan sistem ekonomi liberal, karena sistem ekonomi Islam memiliki tujuan dan panduan yang jelas. Tujuan ekonomi Islam adalah kebahagiaan yang sempurna baik itu secara ruh maupun jasad, kesejahteraan yang membawa ketenangan secara lahir maupun batin. Islam tidak memisahkan kehidupan manusia secara terpisah. Namun, Islam melihat kehidupan sebagai satu kesatuan. ${ }^{3}$ Oleh karena itu, sistem ekonomi Islam tidak berpedoman pada akal pikiran manusia, tetapi sistem ekonomi Islam seratus persen mengikut agama Islam 220 
Syamsuri: Paradigma Pembangunan Ekonomi...

yang bersumber daripada wahyu (al-Quran dan Hadith) dalam berbagai aspeknya.

Kenyataannya sistem ini belum dapat diaplikasikan di Negara belahan dunia mana pun, termasuk Indonesia yang mayoritas penduduknya muslim yang meyakini kebenaran mutlaq akan sistem Ilahi.

\section{Paradigma Pembangunan Ekonomi Liberal}

Setelah terjadinya perang dunia kedua pembangunan ekonomi menjadi satu disiplin pengajian ilmiah ekonomi, khususnya di negara dunia ketiga yang berusaha mendapatkan kemerdekaan dan mengisi kemerdekaan. ${ }^{4}$ Signifikannya pendekatan yang dibawa oleh pembangunan ekonomi liberal telah merasuki berbagai pihak, mereka percaya bahwa pendekatan tersebut mampu menciptakan perubahan baik itu secara sosial, politik maupun ekonomi. ${ }^{5}$ Dua falsafah yang tidak asing lagi dalam berekonomi yaitu kapitalis atau lebih dikenal dengan istilah Falsafah Pasca-Klasikal dan Marxis atau disebut falsafah radikal yang berpegangan dengan kaidah sains sosial barat telah mampu mempengaruhi banyak pandangan hidup manusia (worldview) hingga saat ini. Dua sistem ini berebut pengaruh dan menancapkan hegemoninya pada negara-negara berkembang dalam rentang waktu yang cukup panjang. Sehingga membentuk sebuah doktrin umum, seakan-akan tidak ada pilihan lain dalam menjalankan sistem ekonomi kecuali harus memilih salah satu di antara keduanya. Para ulama, cendikiawan muslim maupun akademisi ditantang untuk dapat mencari alternatif baru selain dari dua sistem tersebut, baik itu dengan cara mengkombinasikan dua sistem ekonomi ke dalam satu sistem ekonomi yang baru atau memunculkan sistem perekonomi yang 100\% berbeda dari kedua sistem di atas.

Salah satu contoh teori yang dikembangkan oleh kedua-dua falsafah itu seperti falsafah pasca-klasikal lahir daripadanya perdagangan bebas (laissez faire), hak-milik bebas, kuasa pasaran dan tingkat pertumbuhan. ${ }^{6}$ Sedangkan falsafah Marxist lahirlah teori sosialisme yang menyatakan bahwa distribusi kekayaan mesti dibagikan secara merata serta penghapusan hak milik pribadi. Sehingga kemaslahatan bersama di atas kemaslatan peribadi. ${ }^{7}$

Menurut A. Mannan kedua falsafah ekonomi tersebut telah gagal dan tidak dapat menyelesaikan masalah yang ada. Hal itu karena sistem ekonomi kapitalis 
Islamiconomic: Jurnal Ekonomi Islam Vol.7 No.2 Juli - Desember 2016

membenarkan orang kaya mengekploitasi orang miskin, dan sistem sosialis membenarkan orang miskin merampas harta orang kaya. ${ }^{8}$ Keduanya bersifat eksploitatif dan tidak fair serta memperlakukan manusia bukan sebagai manusia. ${ }^{9}$ Sebagai contoh dari pandangan sosialisme yaitu lebih menitik beratkan keperluankeperluan hidup manusia dan alat-alat produksinya yang mesti dikuasi dan dimiliki oleh negara. Kepemilikan ini ditujukan agar dapat menghindari keadaan pemerasan kaum pekerja dan pembeli. Bahkan lebih ekstrim lagi dari golongan ini pula muncul aliran atheisme yang tidak mengakui agama dalam berekonomi yaitu golongan Marxist. ${ }^{10}$ Hal ini bukan hanya disebabkan dari perbedaan ideologi, sikap moral dan kerangka sosial politik saja, melainkan lebih pada sifat ekonomi dan duniawi seperti perbedaan sumber alam, situasi ekonomi internasional yang berubah, tingkat ekonomi masing-masing negara dan biaya sosial ekonomi pembangunan yang berlainan. ${ }^{11}$

Kedua falsafah tersebut sepakat bahwa negara-negara berkembang apabila menginginkan kemajuan, maka harus meniru negera-negara Barat yaitu dengan cara menghapus seluruh tradisi dan budaya di negara-negara berkembang, karena keduanya menjadi penghalang kepada pembangunan (cultural block hypothesis).12 Hukum kemajuan bagi kedua falsafah ini yaitu dengan cara memusnahkan masyarakat tradisi yang lebih mengedepankan akhlak, moral dan etika dengan menukar tradisi baru yang diusung dari Barat. Tradisi baru itu mempercayai bahwa manusia mampu menyelesaikan permasalahan kehidupan ekonominya dengan tanpa harus melibatkan aspek akhlak maupun etika dalam berbisnis, ${ }^{13}$ maka agama harus dipisahkan dari aktivitas perekonomian. ${ }^{14}$ Menurut Meir dan Baldwin salah satu sebab kemunduran suatu komunitas hingga tidak berhasil dalam mengatasi masalah ekonomi, tidak lain disebabkan kekurangan ciri indiviualisme di kalangan anggota masyarakat, bahkan agama dan nilai moral yang kaku serta mengekang menjadi penyebab utama kegagalan. ${ }^{15}$

Sistem ekonomi seperti inilah yang menurut Wan Daud merupakan sistem kehewanan (siyasah haywaniyyah) yaitu lebih mengutamakan kehendak-kehendak ekonomi dan menyatakan bahwa kebenaran hanya di tangan penguasa politik maupun penguasa ekonomi. ${ }^{16}$ Dampak dari pelaksanaan kedua atau salah satu dari filsafat ekonomi ini yaitu akan mendorong manusia untuk lebih mengutamakan 222 
Syamsuri: Paradigma Pembangunan Ekonomi...

kebahagiaan di dunia secara materialistik dengan mengabaikan aspek-aspek yang lain seperti moral maupun etika. Hal ini terjadi karena menurut mereka manusia merupakan makhluk ekonomi, bukan sebaliknya yaitu manusia adalah hamba Allah SWT yang mengabdi serta khalifah Allah SWT untuk memakmurkan bumiNya. ${ }^{17}$

Lantas kenapa, Uni Eropa pada akhir-akhir ini memerlukan perubahan system pembangunan ekonomi yang baru? Shabbir Razvi seorang pengamat politik berkembangsaan Inggris menyatakan bahwa masalah utama ekonomi dan krisis hutang Eropa adalah dampak nyata dari sistem Kapitalis yang kotor, korup dan menodai fitrah manusia. ${ }^{18}$ Hal itu karena kapitalisme akan melahirkan ketidaksamaan (inequality) di masyarkat, walau pun secara teoritis kapitalis memberi ruang yang sama kepada setiap individu tetapi kenyataannya sistem ini bersifat diskriminatif yang hanya dikuasai oleh kolongmerat saja. Sekalipun semboyan sistem ini to produce, to produce and to produce, (berproduksi untuk dapat berproduksi lebih besar), maka apabila moto ini diterapkan di lapisan masyarakat akan menimbulkan sikap keserakahan materilalistis yang mengakitbatkan pola hidup yang konsumtif.

Permasalahan hidup dan permasalahan lingkungan seperti bencana alam, kerusakan moral dalam kehidupan masyarakat sosial, pendistribusian pendapatan yang tidak seimbang menyebabkan kemiskinan dan pengangguran yang berlaku berbagai tempat. Termasuk hilangnya sikap kebersamaan antara sesama manusia untuk saling tolong menolong. Ini semua menjadi bukti kegagalan kedua sistem tersebut untuk menyelesaikan masalah sosial ekonomi di masyarakat. Dikotomi antara orang kaya dan orang miskin, perbedaan antara kelompok elit kelas atas dan kelas bawahan sangat nyata sekali. Sekelompok masyakarat duduk dan menikmati kekayaan dengan penuh kenyaman bahkan hingga tahap pembadziran, sedangkan sekelompok yang lain duduk di rumah reot yang tidak layak huni lagi, penuh kekurangan dengan meratapi takdir yang tidak memihak mereka. Persamaan hak (equality) sudah tidak lagi menjadi isu publik yang mesti diselesaikan secara bersama, komitmen persaudaraan (brotherhood) tidak lagi tercipta, nilai-nilai moral sudah tidak lagi menjadi penyaring aktivitas ekonomi.

Sangat memprihatinkan apabila hampir 70 persen penduduk miskin Indonesia saat ini adalah buruh tani yang hampir dekat dengan kemiskinan dan terbelakang. ${ }^{19}$ Fahaman kapitalis maupun sosialis telah menjadikan pemilik modal sebagai 
Islamiconomic: Jurnal Ekonomi Islam Vol.7 No.2 Juli - Desember 2016

penguasa pasar dan menjadikan manusia sebagai hamba pembangunan bukan pembangunan untuk manusia. Kesan dari paradigm ekonomi pembangunan liberal di atas menjadi pintu utama kegagalan dan timbulnya masalah-masalah sosial ekonomi yang berkembang di masyarakat hingga saat ini. Sesuai dengan firman Allah SWT dalam surah al-Rum ayat 41 yang artinya;

Telah nampak kerusakan di darat dan di laut disebabkan perbuatan tangan manusia, Allah SWT menghendaki supaya mereka merasakan sebahagian dari (akibat) perbuatan mereka, agar mereka kembali (ke jalan yang benar).

Menurut Ibnu Kathir dalam kitab tafsir al-Quran al-Karim kerusakan yang dimaksud adalah kerusakan alam yang terlihat oleh kasat mata baik kerusakan itu di daratan maupun di lautan. Bencana alam seperti kekurangan makanan, kegagalan dalam bercocok tanam, banjir maupun gunung meletus menyebabkan kerugian besar bagi umat manusia. Semuanya Allah SWT maksudkan agar manusia dapat merasakan dari apa yang telah mereka kerjakan sehingga mereka kembali ke jalan yang benar yaitu al-Quran dan Sunnah. ${ }^{20}$ Perkara ini terjadi disebabkan kemaksiatan telah menjadi tradisi di masyarakat. Sebagaimana pendapat Abu al-'Aliyah; barang siapa yang berbuat maksiat kepada Allah SWT di muka bumi, sesungguhnya ia telah membuat kerusakan di muka bumi, hal itu karena kemakmuran dan keberkahan rezeki hanya dapat dicapai dengan ketaatan kepada Allah SWT. 21

\section{Pembangunan Ekonomi Dalam Prespektif Islam}

Secara bahasa istilah pembangunan berasal dari kalimat bangun; bangkit, berdiri yang kata derivasi dari bangun yaitu membangun atau pembangunan yang bererti membina, membuat, mendirikan, memperbaiki; membuat supaya maju dan تنمية berkembang. ${ }^{22}$ Dalam istilah Arab modern pembangunan berasal dari kalimat

(Tanmiyyah) yang bermaksud pertumbuhan; dan juga تقدم (Taqaddum) yang bererti maju ke depan atau kemajuan. ${ }^{23}$ Tetapi dalam kamus al-Fareed in Finance \& Economic pembangunan atau development membawa arti kepada تطوير (Tatwir) yaitu

pertumbuhan atau ابتكار (Ibtikar) inovasi. ${ }^{24}$ 
Syamsuri: Paradigma Pembangunan Ekonomi...

Pada dasarnya istilah-istilah pembangunan tersebut apabila merujuk kepada firman-firman Allah SWT dalam al-Quran berasal dari kalimat عمر ('Amara); hidup,

seperti ungkapan عَمَرَ الرَّجُجُ عَمْرًا membawa arti seseorang hidup dalam waktu yang panjang. Kemudian setelah mendapat tambahan (alif, sin dan ta') I menjadi استعمر (Ista'mara) yang berarti menghidupkan atau meramaikan, memakmurkan, membangun atau membuka lahan mati (to explore the land) sesuatu kawasan. ${ }^{25}$

Sebagiamana firman Allah SWT yang termaktub dalam surah Hud ayat 61:

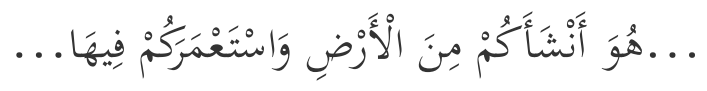

Artinya: Dia telah menciptakan kamu dari bumi (tanah) dan memerintahkan kamu untuk memakmurkan di muka bumi...

Dalam ayat al-Quran tersebut kalimat ista'mara استعمر menurut al-'Alamah alRaghib al-Aîfahani dalam sebuah kitab Mufradatu Alfal̀ al-Quran diambil dari kalimat العِمَارَة (al-'Imarah) yang berarti menguruskan atau memanage, lawan katanya yaitu ألخَرَابُ (al-Kharab) merusak atau meruntuhkan sesuatu. ${ }^{26}$

Sedangkan secara epistimologi pembangunan dalam prespektif Islam yaitu peningkatan kesadaran insan atas tanggungjawabnya terhadap berbagai hakikat dan masalah mengikut urutan keutamaan yang sah, dan amal perbuatan yang ikhlas, berhikmah, berani, sederhana dan adil. Pembangunan ini dapat diukur dengan empat hal utama yaitu kebebasan, keadilan, akhlak dan moral, dan kebahagiaan. ${ }^{27}$ Sekalipun menurut Muhammad Syukri Salleh pembangunan konvensional dan pembangunan yang berdasarkan Islam keduanya mengakui adanya perbedaan dikalangan masyarakat dalam berbagai bidang dan juga menganjurkan agar keadilan dilaksanakan di tengah-tengah perbedaan tersebut. Namun, yang membedakan pembangunan konvensional dan pembangunan Islam adalah konsep perbedaan harta 
Islamiconomic: Jurnal Ekonomi Islam

Vol.7 No.2 Juli - Desember 2016

benda dan konsep keadilan. ${ }^{28}$ Konsep perbedaan harta benda menurut ekonomi liberal disebabkan adanya penindasan dan eksploitasi manusia yang lebih berkemampuan, lebih berpeluang atau lebih berkuasa. Sedangkan dalam Islam perbedaan itu telah Allah SWT jelaskan dalam FirmanNya dalam surah al-An'am ayat 165, yaitu bertujuan sebagai alat Allah SWT menguji manusia dan alat manusia untuk mensyukuri nikmatNya. ${ }^{29}$

Begitu halnya konsep keadilan, mengikut falsafah pembangunan konvensional keadilan lebih berdasarkan pada nilai-nilai materialisme secara kuantitas. Sedangkan Islam melihat keadilan apabila manusia dapat mempertahankan rahmat kepada sekalian alam tanpa derhaka kepada Allah SWT.30 Sesuai dengan pendapat Umer Chapra bahwa masyarakat sekulerisme ${ }^{31}$ lebih mengedepankan harta benda dengan tidak melihat pada aspek moral, maka pembangunan material tidak akan mencapai sebuah keadilan tanpa mendapat dukungan akhlak dan moral. Hal itu karena pembangunan yang adil memerlukan penggunaan semua sumber dengan cara yang efektif dan efisien. Sehingga kedua-duanya mustahil dapat tercapai melainkan dibarengi dengan moral dan akhlak dalam seluruh kegiatan ekonomi. ${ }^{32}$ Hal itu karena, aktivitas ekonomi manusia tidak hanya ditujukan sebagai pemuasan keperluan fisik saja, akan tetapi manusia juga memiliki tanggung jawab kepada Sang Pencipta. ${ }^{33}$ Kebahagiaan di dunia dan di akhirat (falah) tidak dapat dicapai, kecuali jika ajaran Islam dilaksanakan secara menyeluruh atau kaffah. ${ }^{34}$ Sehingga pembangunan ekonomi harus dapat menciptakan keseimbangan antara kepentingan individu dan kepentingan masyarakat, kebaikan yang seimbang dan kekal, ${ }^{35}$ kebaikan yang selaras dengan kaedah-kaedah agama Islam, sehingga kekayaan tidak berhenti pada satu individu atau satu komunitas saja. ${ }^{36}$

\section{Tasawwur Ideologi Islam sebagai Asas Pembangunan Ekonomi}

Islam sebagai tasawwur ideologi umat muslim bersifat universal, bukan hanya sebagai agama tetapi Islam juga merupakan kaedah sosial dan aturan hidup yang lengkap merangkumi dua prinsip yaitu aqidah dan syariah. Aqidah sebagai keyakinan hati bahwa tiada tuhan selain Allah SWT, dan Muhammad SAW adalah rasul-Nya. Setiap muslim memiliki keyakinan bahwa dengan mengikuti seluruh peraturan Allah 
Syamsuri: Paradigma Pembangunan Ekonomi...

SWT akan memberikan kemenangan di dunia maupun di akhirat, sedangkan mengabaikannya akan membawa kesengsaraan yang abadi.

Syariat Islam sebagai petunjuk operasional dalam kehidupan sehari-hari yang mencakupi seluruh keperluan manusia baik itu secara individu maupun bermasyarakat, keperluan untuk hidup di dunia maupun di akhirat nanti. Justru, ideologi Islam adalah sebagai pedoman untuk pembangunan yang telah, maupun sedang berlaku agar lebih menjadi dinamik dan revolusioner. ${ }^{37}$

Islam tidak membedakan agama dengan ekonomi, atau agama dengan politik, tetapi perpaduan antara agama dengan ekonomi adalah kesatuan yang tidak dapat dipisahkan. Apabila terdapat masalah dalam sosioekonomi, bukan berarti Islam tidak lengkap dan tidak memberikan penjelasan tentang masalah tersebut. Akan tetapi, kekurangan para pengikut dan intelek yang mengkaji ke arahnya atau boleh jadi dalam pelaksanaanya umat Islam lebih mengikut konsep yang diusung Barat daripada kembali ke sumber asal (al-Quran dan Hadith). Apabila petunjuk di dalam al-Quran dan Hadith tidak dapat menyelesaikan masalah-masalah ekonomi, maka fungsi akal adalah untuk menalarkannya berdasarkan metode qiyas ${ }^{38}$ atau ijtihad dikalangan ulama. 39

Ziauddin Sardar seorang tokoh pemikiran Islam dalam bukunya Science, policy and development yang dirujuk oleh Muhammad al-Buraey menyatakan bahwa negara Islam pada hari ini adalah Negara yang mengikut model bekas kolonial mereka dalam usaha ke arah pembangunan ekonomi. Tidak ada satu pun Negara Islam di dunia yang berlandaskan dasar pembangunan ekonomi yang mematuhi ideologi Islam. ${ }^{40}$ Tidak heran, apabila mereka telah memadukan antara teori dan ideologi Islam dengan praktek dan ideologi kaum Barat. Hal ini terjadi karena kaum muslimin hanya meyakini sebagian ajaran Islam seperti solat, puasa, zakat dan haji dan meninggalkan sebagian yang lainnya seperti muamalat atau berekonomi dan berpolitik. Sesuai dengan firman Allah SWT dalam surah al-Baqarah ayat 85.

Kasus penduduk negeri Saba' (Yaman) di dalam al-Quran merupakan pelajaran yang penting bagi orang yang beriman terhadap kekuasaan Allah SWT dalam usaha memakmurkan bumi-Nya. Penduduk Saba' hidup dalam kemiskinan di atas padang pasir yang tandus, kemudian Allah SWT airi dengan bendungan menjadikan kawasan 
Islamiconomic: Jurnal Ekonomi Islam Vol.7 No.2 Juli - Desember 2016

$\overline{\text { perkebunan yang subur disebelah kanan maupun kiri negeri Saba'. Sehingga negeri }}$ Saba' penuh kenikmatan dan kesejahteraan dengan limpahan anugerah Allah SWT. Zamakhsari dalam kitab tafsirnya al-Kashshaf memisalkan negeri Saba' pada masa itu seperti surga. ${ }^{41}$ Namun, penduduk Saba' kufur nikmat Allah SWT dan tidak mematuhi peraturan Allah SWT serta mendustakan para Nabi yang diutus-Nya. Hal inilah yang membuat Allah SWT murka dan menimpakan malapetaka berupa binatang tikus untuk membongkar bendungan sehingga bobol dan menenggelamkan perkebenunan negeri Saba'. Bukan itu saja Allah SWT telah mengantikan dua kebun itu dengan dua kebun yang ditumbuhi pohon-pohon yang pahit yaitu athal (sejenis pohon cemara) dan pohon sidr (seperti pohon bidara). ${ }^{42}$ Yang dapat dirujuk di firmanNya dalam surat Saba' ayat 15-16.

Selain itu, Al-Amir Shakib Arsalan sang sejarawan dalam bukunya yang bertajuk limadza ta'akhara al-muslimin wa limadza taqaddama ghairuhum?, dijelaskan bahwa sebab-sebab umat Islam terbelakang dan menjadi mundur pada zaman modern ini yaitu karena umat Islam meninggalkan ajaran Islam yang sempurna, jauh dari panduan Al-Qur'an al-Karim dan al-Sunnah al-Nabawiyyah, dan wujudnya perpecahan antara sesama muslim (al-Tafaruq) yang disebabkan sifat ego. ${ }^{43} \mathrm{Hal}$ ini terjadi karena Islam dan ilmu pengetahuan berjalan seiring, maka meninggalkan al-Quran berarti meninggalkan ilmu pengetahuan. Dampaknya umat Islam merasa rendah diri (Inhizamun al-dakhili) atau (inferior), yang menyebabkan hilangnya percaya diri terhadap Islam (Thiqqatu anfusihim). Sehingga umat Islam akan lebih percaya dengan ajaran Barat secara membabi buta (al-Taqlid). ${ }^{44}$

\section{Dasar Ideologi Pembangunan ekonomi Islam}

Pada dasarnya ideologi pembangunan ekonomi Islam berdasarkan pada firmanfirman Allah SWT di atas termasuk ayat-ayat tentang konsep memakmurkan bumiNya. Seperti kalimat pembangunan yang diambil dari kata استعمر (ista'mara) dalam kitab al-Jami‘ Li Ahkami al-Qur'an karya Abu Bakr al-Qurtubi bermakna perintah Allah SWT kepada umatnya untuk mengelola dan memakmurkan bumi-Nya. Menurut Ibnu al-'Arabi kalimat tersebut membawa arti kepada kewajiban untuk melestarikan bumi Allah SWT, pendapat itu diperkuat oleh Abu Bakar Al-Baqilani 
Syamsuri: Paradigma Pembangunan Ekonomi...

bahwa kalimat yang ber-wazn-kan استفعل (istaf'ala) dalam Lisan al-Arab bermaksud

أفعل perintah untuk melaksakan suatu perbuatan, atau boleh juga menjadi wazn

(af'ala) yang bermaksud merubah perbuatan yang pasif menjadi aktif. Artinya memakmurkan bumi yang sebelumnya tidak ada apapun tanaman untuk ditanami tumbuh-tumbuhan yang dapat memberikan manfaat bagi manusia. ${ }^{45}$ Sekalipun menurut Ibnu 'Amr al-ZamakhsharÊ dalam kitabnya tafsir al-KashÉf perintah untuk memakmurkan bumi Allah SWT bermacam-macam yaitu dari yang wajib hingga ke makruh (dibenci), namun Jumhur Ulama sependapat bahwa memakmurkan bumi dengan cara yang baik adalah hukumnya wajib. ${ }^{46}$

Selain daripada itu pendapat Jumhur Ulama tentang kewajiban memakmurkan bumi di atas dapat diperhatikan daripada analogi-analogi Muhammad Shalt al-Jundiy dalam kitabnya Qawaid al-Tanmiyyah al-Iqtishadiyyah dengan firman Allah SWT dalam al-Qur'an al-karim sebagaimana berikut:

1. Allah SWT tidak menciptakan alam dan isinya melainkan untuk makhlukNya, dengan tujuan dapat beribadah kepada Allah SWT dengan sebaikbaiknya, menjadi khalifah Allah SWT di muka bumi dengan cara menjaga dan memanfaatkan seluruh apa yang ada di dalamnya. Sepertimana firman Allah SWT dalam surat al-Hajj ayat 65.47

2. Setelah Allah SWT menciptakan seluruh makhluk-Nya termasuk jin dan manusia, maka tidak mungkin Ia membiarkan begitu saja melainkan Allah SWT telah mencukupi seluruh keperluannya. Namun, makhluk-Nya mestilah berusaha untuk memenuhi keperluan tersebut dengan cara memakmurkan bumi-Nya. Sesuai dengan firmanNya dalam surah al-Dzariyat ayat 56 - 58 dan surah Hud ayat $6 .^{48}$

3. Tidak ada perbedaan kemuliaan di sisi Allah SWT, selagi manusia itu menjadi khalifah Allah SWT di muka bumi. Dengan adanya tanggung jawab itu, maka Allah SWT telah memberikan kemudahan-kemudahan baik itu di daratan maupun di lautan untuk anak cucu Nabi Adam. Seperti firmanNya dalam surah al-Isra' ayat 70.49 
Islamiconomic: Jurnal Ekonomi Islam Vol.7 No.2 Juli - Desember 2016

Selain dari analog di atas, seluruh ayat yang menjelaskan tentang الكسب (al-

Kasbu), السعى الانغاق (al-Sa'yu), الضرب في الأرض (al-Darfaq) atau fi al-Ardi)50 menjadi asas dasar ideologi pembangunan ekonomi dalam prespektif Islam. Sebagaimana pendapat Munzir QaÍlaf dalam kitabnya al-Nuzul al-Iqtishadiyyah yang dapat difahami melalui firman-firman Allah SWT berikut: 51

1. Kemudahan yang Allah SWT berikan kepada manusia untuk mencari rezeki. Surat Al-Mulk ayat 15:

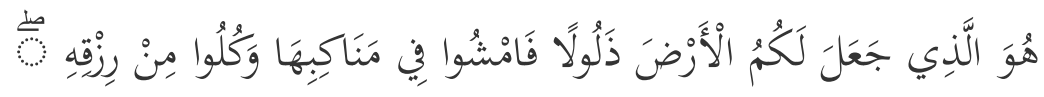

Artinya: Dialah yang menjadikan bumi itu mudah bagi kamu, maka berjalanlah di segala penjurunya dan makanlah sebahagian dari rezekiNya.

2. Kewajiban seoarang ayah untuk memberikan nafkah kepada keluarga. Surat Al-Baqarah ayat 233:

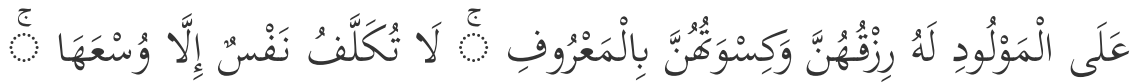

Artinya: Dan kewajipan ayah memberi makan dan pakaian kepada para ibu dengan cara ma'ruf. Seseorang tidak dibebani melainkan menurut kadar kesanggupannya.

3. Kewajiban untuk memberi nafkah kepada semua manusia baik itu kaya maupun miskin. Surat at-Talaq ayat 7:

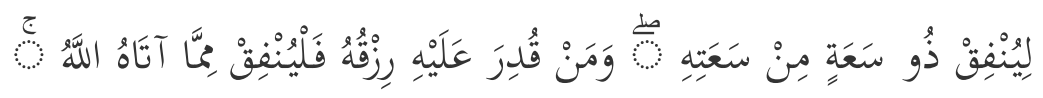

Artinya: Hendaklah orang yang mampu memberi nafkah menurut kemampuannya. Dan orang yang disempitkan rezkinya hendaklah memberi nafkah (semampunya) dari harta yang diberikan Allah SWT kepadanya. 
Syamsuri: Paradigma Pembangunan Ekonomi...

4. Kewajiban mempersiapkan bekal sebelum berperang. Surat al-Anfal ayat 60 yaitu:

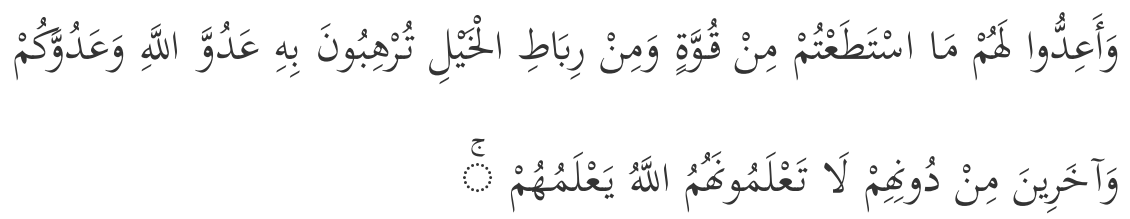

Artinya: Dan siapkanlah untuk menghadapi mereka kekuatan apa saja yang kamu sanggupi dan dari kuda-kuda yang ditambat untuk berperang (yang dengan persiapan itu) kamu menggentarkan musuh Allah SWT dan musuhmu dan orang orang selain mereka yang kamu tidak mengetahuinya; sedang Allah SWT mengetahuinya.

\section{Pendekatan Falsafah Dalam Pembangunan Ekonomi Islam}

Sumber alam yang Allah SWT ciptakan merupakan modal dan perantara untuk memakmurkan bumi Allah SWT sebagai bentuk kesyukuran dan manifestasi tanggungjawab serta pengabdian seorang hamba yang Allah SWT ciptakan dengan sebaik-baik ciptaan tanpa sedikitpun cacat maupun kekurangan. ${ }^{52}$ Tidak heran apabila Allah SWT telah menciptakan seluruh apa yang ada di atas permukaan bumi ini semata-mata hanya diperuntukkan untuk memenuhi keperluan anak cucu nabi Adam AS, karena Allah SWT Maha Tahu dan menganggap manusialah yang layak untuk memakmurkan dan menguruskannya. ${ }^{33}$ Sebagaimana firmanNya dalam surah al-Baqarah ayat 29:

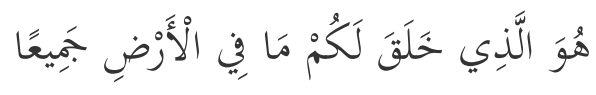

Artinya: Dia-lah Allah SWT, yang menjadikan segala yang ada di bumi untuk kamu.

Oleh karena itu, Allah SWT memberikan syariat atau undang-undang Islam yang ditujukan agar dapat membimbing manusia mencapai nilai kehidupan yang terbaik di dunia dan di akhirat. Syariat Islam telah memastikan adanya kesesuaian di dalam kehidupan manusia, maka apabila peraturan Islam dilaksanakan berdasarkan panduan objektif-objektif syariah yang khusus ataupun umum pasti kestabilan dan keadilan sosioekonomi akan tercapai. ${ }^{54}$ Termasuk juga melihat keseimbangan 
Islamiconomic: Jurnal Ekonomi Islam Vol.7 No.2 Juli - Desember 2016

pandangan Islam (Islam views) dan memperhatikan tujuan yang sejajar dengan pandangan alam. Dalam pandangan alam Islam ada beberapa konsep dasar yang mesti diperhatikan. Dasar-dasar pendekatan falsafah Islam terhadap pembangunan tersebut adalah seperti berikut:

1) Tauhid (Keesaan Tuhan).

Tauhid memiliki makna pengesaan Tuhan sebagai pencipta alam semesta serta segala isinya. Sedangkan cara pengesahannya dengan melaksanakan ibadah yang hanya ditujukan kepada Allah SWT semata. ${ }^{55}$ Tauhid ini menetapkan hukum mengenai perhubungan antara tuhan dengan manusia dan juga antara manusia dengan sesama manusia. ${ }^{56}$ Hubungan antara manusia dengan tuhan maupun sebaliknya, memberi makna bahwa alam semesta ini tidaklah wujud dengan kebetulan atau tanpa direncanakan. Melainkan Allah SWT tuhan yang satulah yang menciptakannya dengan berbagai hikmat yang tersirat disebaliknya. Sehinga hikmat inilah yang menjadikan manusia bernilai dan berarti di alam dunia. Oleh karena itu, manusia dituntut untuk beribadat mentaati tuhan yang satu dengan dikaruniai kuasa ikhtiar, berfikir dan lainya. Tauhid bukan hanya mengakui kebenaran tetapi termasuk juga sambutan aktif kepadanya. ${ }^{57}$ Sebagaimana firmanNya dalam surah Ali ‘Imran ayat 191.

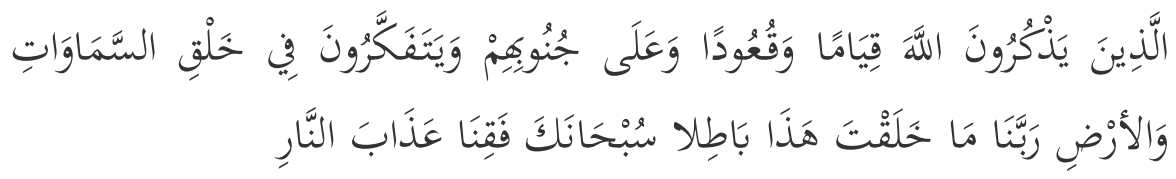

Terjemahan"orang-orang yang mengingat Allah SWT sambil berdiri atau duduk atau dalam keadan berbaring dan mereka memikirkan tentang penciptaan langit dan bumi (seraya berkata): "Ya Tuhan kami, tiadalah Engkau menciptakan ini dengan sia-sia, Maha Suci Engkau, maka peliharalah kami dari siksa neraka."

2) Rububiyyah (Keesaan Dalam Mengurus Alam)

Mengesakan Allah SWT dalam penciptaan, pemberian rezki, pemeliharaan alam semesta, penghancurannya, pencabutan nyawa dan pembangkitan manusia kembali merupakan aplikasi dari keyakinan rububiyyah. Rububiyyah 
Syamsuri: Paradigma Pembangunan Ekonomi...

juga termasuk dalam pengaturan Ilahi untuk penyuburan, kesinambungan kehidupan dan mengarah segala makhluk menuju kepada kesempurnaannya. ${ }^{58}$ Sifat rububiyyah juga mengandungi maksud kepada bimbingan seluruh apa yang Allah SWT ciptakan untuk menuju kebahagian (Sa'adah) di dunia dan di akhirat. Firman Allah SWT dalam surah al-'An'am ayat 164 yaitu;

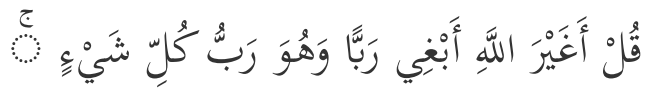

Artinya: Katakanlah: "Apakah aku akan mencari Tuhan selain Allah SWT, padahal Dia adalah Tuhan bagi segala sesuatu.

Makna kalimat Tuhan (Rab) dalam ayat ini memberikan arti bahwa Allah SWT satu-satunya Tuhan yang Mendidik, Menjaga, Mengatur, Mengurus sekalian alam semesta ini yang termasuk di dalamnya menguasai dan memiliki atas segala sesuatu. Sehingga ayat ini mewajibkan setiap muslim untuk bertawakal dan mengikhlaskan segala aktivitas dalam kehidupan di dunia hanya untuk Allah SWT semata. ${ }^{59}$ Inilah hukum dasar alam yang menekankan kepada model pembangunan sumber yang berguna disamping mendorong dan berbagi sumber alam tersebut. ${ }^{60}$ Suatu tata cara yang telah Allah SWT tetapkan bagi menjamin pembangunan sumber-sumber alam agar sentiasa seimbang dan berterusan. ${ }^{61}$ Dalam konteks susunan yang suci inilah usaha manusia dalam hal pembangunan ekonomi dijalankan. ${ }^{62}$

\section{3) ‘Adalah (Kesamaan Hak dan Keharmonian)}

Al-'Adlu atau asal kata dasarnya dari kalimat 'adila ya'dilu yaitu kata pinjaman daripadanya ialah 'adalah bermaksud pertengahan (al-Tawasut) atau tidak berlebihan (Ifrath) dan juga tidak ceroboh (Tafrith), atau lebih tepatnya bermaksud memberikan sesuai dengan haknya.63 Menurut Muhammad Fuad Abdu al-Baqiy kalimat adil dalam al-Quran disebutkan sebanyak 28 kali yang termaktub di dalam 28 ayat pada 11 surat. ${ }^{64}$ Kalimat Adil termaktub dalam berbagai bentuk seperti 'adl, qisÏ, mizan, qâ̂d yang lawan kata dari kalimat tersebut yaitu Dzulm (kezaliman), itsmu (dosa) dan dhalal (kesesatan). ${ }^{65}$ Quraih Shihab mengatakan mayoriti kalimat adil dinisbahkan kepada manusia, 
Islamiconomic: Jurnal Ekonomi Islam Vol.7 No.2 Juli - Desember 2016

sehingga menurut beliau lafaz adil dalam al-quran membawa arti kepada empat makna yaitu adil bererti sama rata. Pertama, adil bermaksud seimbang yaitu lawan kata daripada dzulm (kezaliman) sesuai dengan firman Allah SWT dalam surah al-Nisa' ayat 58. Kedua, adil yang berarti memperhatikan kepada hak-hak individu seperti yang termaktub dalam surah al-Infitar ayat 6-7. Ketiga, Adil memberikan hak-hak itu kepada setiap pemiliknya bertepatan dengan firman Allah SWT dalam surah al-Najmu ayat 38-40. Keempat adil yang dinisbatkan kepada Ilahi. 66

Dengan berbagai makna tersebut, maka secara garis besar 'adalah merupakan suatu keadan di mana setiap manusia mendapatkan kesamaan perlakuan dihadapan hukum, kesamaan hak kompensasi, hak hidup layak, hak menikmati pembangunan dan tidak adanya pihak yang kurang bernasib baik bahkan keseimbangan dalam setiap aspek kehidupan.67 Sehingga adil merupakan nilai paling dasar dalam ajaran Islam, oleh karena menegakkan keadilan dan memberantas kedzaliman merupakan tujuan utama dari risalah para Rasul Allah SWT. Tidak heran apabila kalimat adil selalu bersandingan bahkan sederajat dengan kalimat kebajikan dan ketaqwaan. sebagimana firmanNya dalam surat al-Maidah ayat 8;

Terjemahan: Hai orang-orang yang beriman hendaklah kamu jadi orang-orang yang selalu menegakkan (kebenaran) karena Allah SWT, menjadi saksi dengan adil. Dan janganlah sekali-kali kebencianmu terhadap sesuatu kaum, mendorong kamu untuk berlaku tidak adil. Berlaku adillah, karena adil itu lebih dekat kepada takwa.

4) Khilafah (peran manusia).

Khilafah merupakan kesadaran seseorang terhadap amanah dan tangungjawab yang Allah SWT bebankan sebagai penganti utusan-Nya di muka bumi. Tanggungjawab sebagai insan kamil dalam bentuk perilaku antara manusia dengan rabnya, manusia dengan manusia dan manusia dengan alam sekitarnya. 
Syamsuri: Paradigma Pembangunan Ekonomi...

Nilai khilafah menciptakan mashlahah yang maksimal dan mencegah kerusakan di muka bumi termasuk usaha-usaha dalam memakmurkan bumi Allah SWT dengan konsep Islam. Sehingga segala perlakuan manusia dalam rangka memakmurkan bumi mestilah tunduk sepenuhnya kepada kehendak Allah SWT. ${ }^{68}$ Kepemilikan, pemanfaatan sumber alam mesti dalam batas sewajarnya tidak membuat kerusakan dan melampaui batas. ${ }^{69}$ Sebagaimana firman Allah SWT dalam surah Al-Baqarah ayat ke-30.

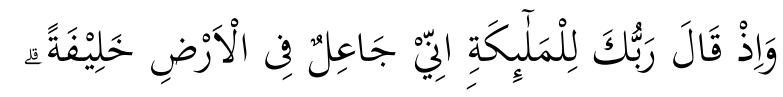

Al-Baqarah (2): 30

Terjemahan: Ingatlah ketika Tuhanmu berfirman kepada para Malaikat: sesungguhnya Aku hendak menjadikan seorang khalifah di muka bumi.

Menurut Imam Ibnu Kathir ayat di atas membawa maksud kepada tangungjawab dan amanah yang Allah SWT berikan kepada seluruh manusia, bukan hanya kepada nabi Adam a.s. sepertimana pendapat para mufasir umumnya. ${ }^{70}$ Amanah tersebut yaitu kewajipan memelihara, memakmurkan, maupun mengelola sumber alam untuk kemaslahatan ummah dari generasi ke generasi selanjutnya. ${ }^{71}$ Bahkan amanah paling besar yang dibebankan kepada setiap individu yaitu dirinya sendiri yang meliputi anggota badan, masa dan tenaga. ${ }^{72}$ Tugas mencegah pencemaran alam sekitar dan pemanfaatan sumber alam yang berlebihan (al-TaÏarruf) sehingga memudaratkan generasi sekarang maupun akan datang juga menjadi tangung jawab setiap individu. Hal ini sesuai dengan objektif syariah (MaqÉsid al-sharÊah) yaitu mencegah kemudaratan lebih baik daripada mengambil manfaat. Dengan demikian pembangunan bersama keadilan bisa dianggap berhasil apabila tuntutan khilafah dan 'adalah dipenuhi melalui pemenuhan keperluan setiap insan, distribusi pendapatan dan kekayaan secara adil, penggunaan tenaga penuh dan perlindungan alam sekitar. ${ }^{73}$ Hal itu karena tumpuan pembangunan di dalam masyarakat Islam ialah menyediakan keperluan dasar bagi seluruh masyarakat, selalu 
Islamiconomic: Jurnal Ekonomi Islam

Vol.7 No.2 Juli - Desember 2016

mengharapkan kebaikan bagi saudara Islamnya seperti kebaikan yang diharapkan untuk dirinya sendiri. ${ }^{74}$

5) Tazkiyyah (penyucian serta pertumbuhan) ${ }^{75}$

Tazkiyyah atau taÏhÊr artinya mensucikan atau pertumbuhan dan kebaikan (alIÎlÉ ́́. Secara epistimologi tazkiyyah berarti kebersihan dan perlakuan yang memiliki metode dan teknik, sifatnya dari syariat, dan kesannya terhadap tingkah laku serta usaha untuk mencari keredhaan Allah SWT 76 Tugas semua nabi yang diutuskan Allah SWT tidak lain untuk menyempurnakan tazkiyyah manusia dalam semua hubungannya. Contohnya dengan Allah s.w.t, dengan manusia, dengan alam sekitar dan dengan masyarakat maupun negara. ${ }^{77}$ Sebagaimana Nabi Muhammad s.a.w. diutuskan di muka bumi ini tidaklah lain untuk menyucikan ummatnya. Setidaknya penyucian yang telah beliau lakukan sejak diangkat menjadi rasul-Nya yaitu membersihkan aqidah daripada perbuatan syirik, menyucikan akhlak daripada perbuatan maksiat yang telah menjadi tradisi kaum jahiliyyah dan menyucikan harta dari perkara-perakara yang subhat maupun gharar kepada halal dan tayyib (baik).

Melalui konsep tazkiyyah inilah manusia dapat mengembangkan dirinya yang akhirnya dapat membangunkan semua demensi kehidupannya termasuk dimensi ekonomi. Selanjutnya hasil daripada konsep tazkiyyah ini ialah al-falah yaitu kesejahteraan kehidupan di dunia dan di akhirat. ${ }^{78}$

\section{Penutup}

Paradigma pembangunan ekonomi liberal telah menjadi acuan konsep maupun teori ekonomi pembangunan di berbagai belahan dunia. Hukum kemajuan menurut mereka mesti dengan cara memusnahkan masyarakat tradisi yang lebih mengedepankan akhlak, moral dan etika dengan menukar tradisi baru yang diusung dari Barat. Tradisi baru itu mempercayai bahwa manusia mampu menyelesaikan permasalahan kehidupan ekonominya dengan tanpa harus melibatkan aspek akhlak maupun etika dalam berbisnis, maka agama mesti dipisahkan daripada aktiviti ekonomi. Akan tetapi hingga saat ini kemiskinan, kerusakan alam dan berbagai 
Syamsuri: Paradigma Pembangunan Ekonomi...

bentuk ketimpangan social ekonomi, politik terjadi dimana-mana. Bahkan krisis hutang di eropa juga tidak kunjung selesai, tidak lain disebabkan karena dampak nyata dari system kapitalis yang kotor, korup dan menodai fitrah manusia. Maka kegagalannya menjadi satu pengajaran penting bagi ekonom muslim yang mesti menghadirkan satu teori dan konsep baru bersumberkan kitab quran maupun hadith. Setidaknya islam memberikan lima pendekatan dalam menyelesaikan masalah ini yaitu dengan dasar-dasar falsafahnya tauhid, rububiyyah, khilafah, 'adalah, tazkiyyah.

\section{Pustaka Acuan}

Abdul Rahman b Rukaini, "Peranan Pelajar Dalam Pembangunan Negara”, dalam Kertas Kerja Nadwah Kepemimpinan Islam Sekolah-Sekolah Berasrama Penuh dari Tahun 1981 Hingga 1984, ed. Unit Dakwah Bahagian Pendidikan Islam Kementerian Pelajaran Malaysia (Kementerian Pelajaran Malaysia:t.p., 1997),

Abdullah M. Farid, Dictionary Al- Fareed in Finace \& Economic, ed.ke-1 (Cairo: t.p., 1985), 81, entri “erat."

Abulhassan Muhammad Sadeq, Pembangunan Ekonomi Dalam Islam, terj. Rohani Sulaiman, ed.ke-3 (Kuala Lumpur: Utusan Publication dan Distributor Sdn Bhd,2003)

Adiwarman Azra, Sejarah pemikiran Ekonomi Islam, (Jakarta: Internasional Institute Of Islamic Thought,2001),

Ahmad Shukri Mohd. Naim et al., Konsep, Teori, Dimensi \& Isu Pembangunan, ed.ke1(Johor, Skudai: Universiti Teknologi Malaysia, 2003),

Amri Amrullah, Ekonom Inggris: kapitalisme biang kehancuran ekonomi global, situs resmi, Republika.co.id, diunduh tanggal 5/11/2016.

Asmuni Mth,"Konsep Pembangunan Ekonomi Islam", Jurnal Al-Mawarid, Edisi X Tahun 2003, Universitas Islam Indonesia, Jogjakarta, 2003)

Ed. Baharuddin Yatim et al., Konsep Pembangunan dan Kenegaraan Malaysia, ed.ke-1 (Bangi: Pusat Pengajian Umum Universiti Kebangsaan Malaysia,1989)

Jomo K.S et al., Teori Pembangunan Ekonomi, (Kuala Lumpur: Utusan Publication, 2004)

Joni Tamkin b Borhan, "Pemikiran Pembangunan Ekonomi Berteraskan Islam," Jurnal Usuluddin 1, no. 27 
Islamiconomic: Jurnal Ekonomi Islam Vol.7 No.2 Juli - Desember 2016

Khurshid Ahmad, "Pembangunan Ekonomi Dalam Perspektif Islam," dalam Etika Ekonomi Politik, ed. Ainur R. Sophiaan et al., (Surabaya: Risalah Gusti, 1997)

Ahmad Shukri Mohd. Naim et al., Konsep, Teori, Dimensi \& Isu Pembangunan, ed.ke-1. Johor, Skudai: Universiti Teknologi Malaysia, 2003.

Ambo Asse, "Konsep Adil Dalam Al-Quran”," Jurnal Al-Risalah 10, no. 2 (2010)

David Krisna Alka, "Moralitas, kemiskinan dan agamawan" dalam Islam Madzhab Tengah, Persembahan 70 Tahun Tarmizi Taher, ed. Hery Sucipto et al., (Jakarta Selatan: Grafindo Khazanah Ilmu, 2007)

G.V. Plekhanov Fundamental Problem of Marxism, Masalah-Masalah Dasar Marxisme, terj. Ira Iramanto (t.tp. 2007)

M. Umer Chapra, Islam And Economic Development (Pakista, Islamabad: Internasional Institute of Islamic Thought, 1981)

M. Umer Chapra, Islam dan Pembangunan Ekonomi, Satu Stategi untuk Pembangunan yang adil dan stabil, terj. Adi Setia B Mohd Dom (Petaling Jaya: The international Institute Of Islamic Thought, 1997)

Moch Khaoirul Anwar, "Ekonomi dalam Perspektif Islam," Jurnal Islamica 3, no. 1 (September 2008)

Mohamed Ariff, "Pembangunan Ekonomi Menurut Perspektif Islam," dalam Konsep dan Pelaksanaan Pembangunan Berteraskan Islam, ed. Muhammad Syukri Salleh (Pulau Pinang: Universiti Sains Malaysia, 1990),

Mohd. Radzi Othman et al., Ekonomi Dalam Perspektif Al-Quran dan al-Sunnah (Pulau Pinang: Universitas Sains Malaysia, 2005),

Mohd. Radzi Othman et al., Ekonomi Dalam Perspektif Al-Quran dan al-Sunnah. Pulau Pinang: Universitas Sains Malaysia, 2005.

Muhammad Al-Buraey, Pembangunan Pentadbiran menurut Perspektif Islam, terj. Abdullah (Kuala Lumpur: Dewan Bahasa dan Pustaka, 1992),

Muhammad Fuad Abdu al-Baqiy, Mu'jam al-Mufahras li al-Fadz al-Qur'an (Indonesia: Maktabah Dakhlan, 1939),

Muhammad Kamal Hassan, "Pembangunan yang Berteraskan Islam," dalam Konsep dan Pelaksanaan Pembangunan Berteraskan Islam, ed. Muhammad Syukri Salleh (Pulau Pinang: Universiti Sains Malaysia, 1990), 
Syamsuri: Paradigma Pembangunan Ekonomi...

Muhammad Syukri Salleh, Pembangunan berteraskan Islam, (Petaling Jaya: Fajar Bakti, 1987),

Muhammad Syukri Salleh, Tujuh Prinsip Pembangunan Berteraskan Islam, ed.ke-1 (Kuala Lumpur: Zebra Editions,2003),

Pusat Pengkaji dan Pengembangan Ekonomi Islam (P3EI) Universiti Islam Indonesia Yogyakarta et al., Ekonomi Islam,

Ruma Mubarak, "Strategi Pendidikan Islam Dalam Meningkatkan Kualitas Sumber Daya Manusia,"Jurnal el-Hikmah 10, no. 1(2012),

Said Aqiel Siradj, "Tauhid dalam perspektif tasawuf", Jurnal Islamica 5, no. 1 (September 2010),

Surtahman Kastin Hasan,"Konsep Pembangunan Islam" dalam Konsep Pembangunan dan Kenegaraan Malaysia, ed. Baharuddin Yatim et al., ed. ke-1 (Bangi: Pusat Pengajian Umum Universiti Kebangsaan Malaysia,1989),

Syed Hussein Alatas, Islam dan sosialisma (Pulau Pinang: Seruan Masa, 1976),

Tim Redaksi Kamus Bahasa Indonesia, Kamus Bahasa Indonesia, (Jakarta: Pusat Bahasa Departemen Pendidikan Nasional Indonesia,2008), 135, entri “erat."

Wan Mohd Nor Wan Daud, Pembangunan di Malaysia ke arah satu kefahaman baru yang lebih sempurna, ed. ke-5. Kuala Lumpur: Jabatan Akidah dan Pemikiran Islam, Akademi Pengajian Islam Universiti Malaya,2005.

\section{Catatan Akhir:}

\footnotetext{
${ }^{1}$ Wan Mohd Nor Wan Daud, Pembangunan di Malaysia ke arah satu kefahaman baru yang lebih sempurna, 11.

${ }^{2}$ Lihat, Moch Khaoirul Anwar, "Ekonomi dalam Perspektif Islam," Jurnal Islamica 3, no. 1 (September 2008), 27.

3 Adiwarman Azra, Sejarah pemikiran Ekonomi Islam, (Jakarta: Internasional Institute Of Islamic Thought,2001), 23.

4 Abdul Rahman b Rukaini, "Peranan Pelajar Dalam Pembangunan Negara", dalam Kertas Kerja Nadwah Kepemimpinan Islam Sekolah-Sekolah Berasrama Penuh dari Tahun 1981 Hingga 1984, ed. Unit Dakwah Bahagian Pendidikan Islam Kementerian Pelajaran Malaysia (Kementerian Pelajaran Malaysia:t.p., 1997), 48 .

5 Ahmad Shukri Mohd. Naim et al., Konsep, Teori, Dimensi \& Isu Pembangunan, ed.ke-1(Johor, Skudai: Universiti Teknologi Malaysia, 2003), 180.

${ }^{6}$ Lihat, G.V. Plekhanov Fundamental Problem of Marxism, Masalah-Masalah Dasar Marxisme, terj. Ira Iramanto (t.tp. 2007), 70

${ }^{7}$ Lihat, Ibid.,

${ }^{8}$ Ahmad Shukri Mohd. Naim et al. (eds) Konsep, Teori, Dimensi \& Isu Pembangunan, 84.

9 Khurshid Ahmad, "Pembangunan Ekonomi Dalam Perspektif Islam," dalam Etika Ekonomi Politik, ed. Ainur R. Sophiaan et al., (Surabaya: Risalah Gusti, 1997),7.
} 
${ }^{10}$ Syed Hussein Alatas, Islam dan sosialisma (Pulau Pinang: Seruan Masa, 1976), 4.

${ }^{11}$ Khurshid Ahmad, "Pembangunan Ekonomi Dalam Perspektif Islam," dalam Etika Ekonomi Politik, 8.

12 Muhammad Syukri Salleh, Tujuh Prinsip Pembangunan Berteraskan Islam, ed.ke-1 (Kuala Lumpur: Zebra Editions,2003), 8.

13 Surtahman Kastin Hasan,"Konsep Pembangunan Islam" dalam Konsep Pembangunan dan Kenegaraan Malaysia, ed. Baharuddin Yatim et al., ed. ke-1 (Bangi: Pusat Pengajian Umum Universiti Kebangsaan Malaysia,1989), 1.

${ }^{14}$ Ed. Baharuddin Yatim et al., Konsep Pembangunan dan Kenegaraan Malaysia, ed.ke-1 (Bangi: Pusat Pengajian Umum Universiti Kebangsaan Malaysia,1989), 1.

15 Jomo K.S et al., Teori Pembangunan Ekonomi, (Kuala Lumpur: Utusan Publication, 2004), 30-31.

${ }^{16}$ Wan Mohd Nor Wan Daud, Pembangunan di Malaysia ke arah satu kefahaman baru yang lebih sempurna, 11.

${ }^{17}$ Muhammad Syukri Salleh, Tujuh Prinsip Pembangunan Berteraskan Islam, 11.

18 Amri Amrullah, Ekonom Inggris: kapitalisme biang kehancuran ekonomi global, situs resmi, Republika.co.id, diunduh tanggal 5/11/2016.

19 Lihat, David Krisna Alka, "Moralitas, kemiskinan dan agamawan" dalam Islam Madzhab Tengah, Persembahan 70 Tahun Tarmizi Taher, ed. Hery Sucipto et al., (Jakarta Selatan: Grafindo Khazanah Ilmu, 2007), 215.

${ }^{20}$ Al-ImÉm al-×ÉfiÌ 'ImÉdu al-DÊn AbÊ al-FidÉ' Isma'Êl bin 'Umar Ibnu KathÊr al-DamashqÊ, Tafs $\hat{E} r$ alQurÉn al- 'AİEm (Bierut: DÉr al-Kutub al-'Ilmiyyah,1998), 6:288.

${ }^{21}$ Ibid.

${ }^{22}$ Tim Redaksi Kamus Bahasa Indonesia, Kamus Bahasa Indonesia, (Jakarta: Pusat Bahasa Departemen Pendidikan Nasional Indonesia,2008), 135, entri "erat."

23 Wan Mohd Nor Wan Daud, Pembangunan Di Malaysia kea rah satu kefahaman baru yang lebih sempurna, 14

${ }^{24}$ Abdullah M. Farid, Dictionary Al-Fareed in Finace \& Economic, ed.ke-1 (Cairo: t.p., 1985), 81, entri "erat."

${ }^{25}$ IbrahÊm MuIIIofÉ et al., al-Mu’jam al-Was Ê̈̈, ed.ke-1 (IstanbËl: Turki al-Maktabah al-IslÉmiyyah, 1972), 1:626 - 627, entri "erat."

26 al-'AlÉmah al-RÉghib al-AÎfahÉnÊ, MufradÉtu AlfÉİ al-QurÉn, (BÊrËt: al-DÉr al-ShÉmiyyah, 1992), 586.

${ }^{27}$ Wan Mohd Nor Wan Daud, Pembangunan di Malaysia ke arah satu kefahaman baru yang lebih sempurna, 19.

${ }^{28}$ Lihat. Muhammad Syukri Salleh, Pembangunan berteraskan Islam, (Petaling Jaya: Fajar Bakti, 1987), 49.

${ }^{29}$ Lihat. Ibid

${ }^{30}$ Lihat. Ibid, h. 50

${ }^{31}$ Masyarakat sekuler ialah masyarakat yang percaya bahwa urusan Negara, sistem pendidikan, ekonomi, sosial, kesenian, moral serta sains dan teknologi tidak ada hubungannya dengan agama. Sekularisasi dapat dicapai melalui proses modenisasi. Lihat, Ahmad Shukri Mohd. Naim et al., Konsep, Teori, Dimensi \& Isu Pembangunan, 132.

${ }^{32}$ M. Umer Chapra, Islam And Economic Development (Pakista, Islamabad: Internasional Institute of Islamic Thought, 1981), 7.

${ }^{33}$ Ibid

${ }^{34}$ Pusat Pengajian dan Pengembangan Ekonomi Islam (P3EI), Ekonomi Islam,16.

35 Abulhassan Muhammad Sadeq, Pembangunan Ekonomi Dalam Islam, terj. Rohani Sulaiman, ed.ke-3 (Kuala Lumpur: Utusan Publication dan Distributor Sdn Bhd,2003) h.2.

${ }^{36}$ Lihat, Seminar Nasional, Pembangunan Ekonomi Dalam Pandangan Islam, 53-54.

37 Muhammad Al-Buraey, Pembangunan Pentadbiran menurut Perspektif Islam, terj. Abdullah (Kuala Lumpur: Dewan Bahasa dan Pustaka, 1992), 1.

${ }^{38}$ Qiyas secara syarak yaitu dengan membandingkan suatu perkara yang baru wujud dengan hokum nash yang telah sedia ada yaitu al-quran atau hadith

${ }^{39}$ Lihat, Seminar Nasional, Pembangunan Ekonomi Dalam Pandangan Islam, 53-54.

${ }^{40}$ Muhammad Al-Buraey, Pembangunan Pentadbiran menurut Perspektif Islam, 139. 
${ }^{41}$ AbÊ QÉsim MaÍmËd bin 'Amr al-ZamakhsharÊ, al-KashÉf, ed.ke-1(Riyadh: Maktabah al-'AbaikÉn, 1998), 3:115.

${ }^{42}$ Al-ImÉm al-×ÉfiĐ 'ImÉdu al-DÊn AbÊ al-FidÉi IsmÉ’Êl bin 'Umar Ibnu KathÊr al-DamashqÊ, Tafsêr al-QurÉn al-'AĐÊn, (BierËt: Lebanon, DÉr al-Kutub al-'Ilmiyyah, 1999) 6: 448-449.

${ }^{43} \mathrm{Al}$-AmÊr ShakÊb ArsalÉn, limÉdza ta'akhara al-muslimËn wa limÉdza taqaddama qhairum ? (BierËt: Lebanon, DÉr maktabah al-ÍayÉt, 2008), 131-140.

${ }^{44}$ Ibid., 142.

${ }^{45}$ AbÊ Abdi Allah Muhammad bin AÍmad bin AbÊ Bakr al-QurÏubÊ, al-JÉmi 'LiaÍkÉmi al-QurÉn, ed.ke-1 (BierËt: Lebanon, al-RisÉlah, 2006), 12: 149-150.

${ }^{46}$ AbÊ QÉsim MaÍmËd bin 'Amr al-ZamakhsharÊ, al-KashÉf, ed.ke-1, (Riyadh: Maktabah al-'AbaikÉn, 1998), 3: 212-213.

${ }^{47}$ MuÍammad al-ShaIÉt al-Jundiy, QawÉid al-Tanmiyyah al-Iqtî́Édiyyah fêE al-QanËn al-DaulÊ wa al-Fiqh al-IslÉmÊ, (al-QÉhirah: DÉr al-NahÌah al-’Arabiyyah, 1985), 28.

${ }^{48}$ Ibid., 29

${ }^{49}$ MuÍammad al-ShaIÉt al-Jundiy, QawÉid al-Tanmiyyah al-Iqtî́Édiyyah fế al-QanËn al-DaulÊ wa al-Fiqh al-IslÉm $\hat{E}, 30$

50 Asmuni Mth,”Konsep Pembangunan Ekonomi Islam", Jurnal Al-Mawarid, Edisi X Tahun 2003, Universitas Islam Indonesia, Jogjakarta, 2003), 132.

${ }^{51}$ Munzir QaÍaf, al-Nuzul al-Iqtishadiyyah min al-QurÉn wa al-Sunnah, (Jeddah: JÉmi’ah Mamlakah Abd al-'AzÊz, 1995), 50.

${ }^{52}$ Ibnu Qayyim al-Jauziyyah, BadÉi’ al-TafsÊrr, ed.ke-1 (Al-QÉhirah: DÉr al-JauzÊ, 2006), 3:335.

${ }^{53}$ Al-ImÉm al-×ÉfiĐ Abd al-RaÍman Bin MuÍammad ibnu IdrÊs al-RÉzÊ Ibnu AbÊ ×Étim, TafsÊr al-QurÉn al- 'AĐÊm (Riyal̀: Maktabah NizÉr MusïafÉ al-BÉz, 1997), 1:75.

${ }^{54}$ M. Umer Chapra, Islam dan Pembangunan Ekonomi, Satu Stategi untuk Pembangunan yang adil dan stabil, terj. Adi Setia B Mohd Dom (Petaling Jaya: The international Institute Of Islamic Thought, 1997), 6.

${ }^{55}$ Said Aqiel Siradj, “Tauhid dalam perspektif tasawuf”, Jurnal Islamica 5, no. 1 (September 2010), 153.

${ }^{56}$ Khurshid Ahmad, "Pembangunan Ekonomi Dalam Rangka Kerja Islam," 270.

${ }^{57}$ M. Umer Chapra, Islam dan Pembangunan Ekonomi, Satu Stategi untuk Pembangunan yang adil dan stabil, 7.

${ }^{58}$ Muhammad Al-Buraey, Pembangunan Pentadbiran menurut Perspektif Islam, 150.

${ }^{59}$ Al-ImÉm al-×Éfì̀ ‘ImÉdu al-DÊn AbÊ al-FidÉ’ Isma’Êl bin ‘Umar Ibnu KathÊr al-DamashqÊ ,Tafsêr alQurÉn al- 'AİEm (Bierut: DÉr al-Kutub al-'Ilmiyyah, 1998), 3:245.

${ }^{60}$ Muhammad Al-Buraey, Pembangunan Pentadbiran menurut Perspektif Islam, 150.

${ }^{61}$ Muhammad Shukri Salleh, Konsep dan Pelaksanaan Pembangunan Berteraskan Islam, 5.

${ }^{62}$ Khurshid Ahmad, "Pembangunan Ekonomi Dalam Rangka Kerja Islam," 271.

${ }^{63}$ AÍmad al-Sharbaî̂E, al-Mu'jam al-IqtîÉÉÊ al-IslÉmÊ (Kaherah: DÉr al-Jail, 1981), 289.

${ }^{64}$ Lihat, Muhammad Fuad Abdu al-Baqiy, Mu'jam al-Mufahras li al-FÉdz al-QurÉn (Indonesia: Maktabah Dakhlan, 1939), 569-570.

${ }^{65}$ Pusat Pengkaji dan Pengembangan Ekonomi Islam (P3EI) Universiti Islam Indonesia Yogyakarta et al., Ekonomi Islam, 59.

${ }^{66}$ Ambo Asse, “Konsep Adil Dalam Al-Quran”," Jurnal Al-Risalah 10, no. 2 (2010), 277.

${ }^{67}$ Pusat Pengkaji dan Pengembangan Ekonomi Islam (P3EI) Universiti Islam Indonesia Yogyakarta et al. (eds), Ekonomi Islam, 59.

${ }^{68}$ Mohd. Radzi Othman et al., Ekonomi Dalam Perspektif Al-Quran dan al-Sunnah (Pulau Pinang: Universitas Sains Malaysia, 2005),110.

${ }^{69}$ Pusat Pengkaji dan Pengembangan Ekonomi Islam (P3EI) Universiti Islam Indonesia Yogyakarta et al., Ekonomi Islam, 62. 
Islamiconomic: Jurnal Ekonomi Islam Vol.7 No.2 Juli - Desember 2016

${ }^{70}$ Al-ImÉm al-×Éfil ‘ImÉdu al-DÊn AbÊ al-FidÉ’ Isma'Êl bin ‘Umar Ibnu KathÊr al-DamashqÊ , Tafsêr alQurÉn al-'AİEm, 1: 124.

${ }^{71}$ Ibid., 3: 246.

${ }^{72}$ Mohd. Radzi Othman et al., Ekonomi Dalam Perspektif Al-Quran dan al-Sunnah, 133.

${ }^{73}$ Umer Chapra, Islam dan Pembangunan Ekonomi, Satu Stategi untuk Pembangunan yang adil dan stabil, 6.

${ }^{74}$ Mohamed Ariff, "Pembangunan Ekonomi Menurut Perspektif Islam," dalam Konsep dan Pelaksanaan Pembangunan Berteraskan Islam, ed. Muhammad Syukri Salleh (Pulau Pinang: Universiti Sains Malaysia, 1990), 22.

${ }^{75}$ Muhammad Kamal Hassan, "Pembangunan yang Berteraskan Islam," dalam Konsep dan Pelaksanaan Pembangunan Berteraskan Islam, ed. Muhammad Syukri Salleh (Pulau Pinang: Universiti Sains Malaysia, 1990), 22.4

${ }^{76}$ Ruma Mubarak, "Strategi Pendidikan Islam Dalam Meningkatkan Kualitas Sumber Daya Manusia,"Jurnal el- Hikmah 10, no. 1(2012), 123.

${ }^{77}$ Khurshid Ahmad, "Pembangunan Ekonomi Dalam Rangka Kerja Islam,” 271.

${ }^{78}$ Joni Tamkin b Borhan, "Pemikiran Pembangunan Ekonomi Berteraskan Islam,” 97. 